\title{
Natural Lime Treated as Partial Cement Replacement to Produce Concrete
}

\author{
Tan Yeong Yü, Doh Shu Ing ${ }^{*}$, Chin Siew Choo ${ }^{*}$, Muhammad Aizat Azed* \\ ${ }^{\#}$ Master Student in Faculty of Civil Engineering and Earth Resources, University Malaysia Pahang, 26300 Kuantan, Malaysia \\ E-mail: tanyeongyu@gmail.com \\ ${ }^{*}$ Faculty of Civil Engineering and Earth Resources, University Malaysia Pahang, 26300 Kuantan, Malaysia \\ E-mail:dohsi@ump.edu.my,scchin@ump.edu.my
}

\begin{abstract}
In this study, the eggshell powder was used as partial replacement of Ordinary Portland cement replacement at 5\%, $10 \%$, $15 \%$ and $20 \%$ in concrete production. Since the chemical compositions of eggshell contain mainly of calcium oxide which is mostly similar to the natural lime sources. Thus the use of waste-products in cement industries is an environmental friendly while able to increase the industrialization instead of disposal of large numbers of waste materials that would pollute the land, water, and air. The specimens were casted into concrete cube $(100 \mathrm{~mm} \times 100 \mathrm{~mm} \times 100 \mathrm{~mm})$ and beam $(100 \mathrm{~mm} \times 100 \mathrm{~mm} \times 500 \mathrm{~mm})$. The investigations focused on compressive, flexural strength and water absorption at different percentages of replacement and tested at 1, 7, 28, 56 and 90 days. From the investigation, it is found that the compressive strength and flexural strength increases up to $45 \%$ as compared to the control specimens when cement replacement by $15 \%$ of air-dry eggshell powder. Moreover, the rate of water absorption greatly reduces $55 \%$ when cement replacement by $15 \%$ of air-dry eggshell powder. Scanning electron microscope showed a clear picture of the eggshell concrete contains fewer voids than normal plain concrete.
\end{abstract}

Keywords - eggshell powder; partial cement replacement; compressive strength; flexural strength; water absorption; scanning electron microscope

\section{INTRODUCTION}

Cement is known as the most used substances besides than the water in the earth because of its properties which had the ability to be able to cast into any desired shape, ability to be fabricated as well as durability has become well-known over the years [1]. Moreover, cement is the generally expensive than other materials of concrete. Furthermore, cement production may consume lots of energy. In addition, it is a source of the greenhouse gas emission with approximately $130 \mathrm{~kg}$ of fuel and $110 \mathrm{KWh}$ of electricity required in order to produce each tons ordinary Portland cement (OPC) which emit around 0.9 tons of carbon dioxide [2].

Annual manufacture of the cement is approximately 3.6 billion metric tons, yet the consumption of the OPC is still increasing significantly, and it is predicted that it could rise up to 5 billion metric tons by 2030. Since the interest of using the cement will continue to increase in the future. Thus eggshell may be another low-cost energy-saving replacements material for cement industry that should look into [3]. Eggshell is known as agricultural waste that produced from chicken hatcheries, bakeries, fast-food restaurants. It is traditionally useless in any field and treated as landfill.

Besides that, eggshell will also create some unpleasant smell when it kept for long period of time in the garbage., disposal of the eggshell may attract rats or worms due to the rich organic protein matrix that available in the eggshell [4]. Moreover, the eggshell may possess undesirable smell which may cause irritation [5]. Eggshell contains much growing of calcium carbonate $(\mathrm{CaCO} 3)$.Most of the eggshell consists of calcium, magnesium carbonate, and protein. Thus, the source of the calcium is almost similar to the lime that uses in the cement [6].

Reuse of wastes materials is generally known as one of the best environmental solutions in order to solve the issue of the disposal. Eggshells are known as one of the waste materials which rich in calcium carbonate. The reuse of the eggshell in the concrete industry not only overcome the eggshells disposal issue which for example in the America, the food industry may produce approximately 150,000 tons of eggshell waste, thus reuse of the eggshell in the concrete production may also produce the constituents more economical. 
In general, the quality of the eggshell can be influenced by many aspects such as the type of chicken, daily diet, and stress related to the population density [7]. Thus, the condition of calcium in the eggshell waste may be greatly affected by the raw water and harsh weather conditions. An ideal method is an eggshell should be dried at original place, subsequently, send to the required site where it would be ground immediately and used as the origin of calcium or lime to other applications.

In this investigation, three experiments namely compressive strength, flexural strength, and water absorption were conducted to analyse the performance of the eggshell. All the tests were tested in triplicate and average of the values are recorded. Scanning electron microscope (SEM) was performed to analysis the details of the concrete specimens. Through SEM analysis able to justify the reaction between the cement and eggshell powder.

\section{MATERIAL AND METHOD}

\section{A. Materials Used}

Ordinary Portland cement (OPC) was used in the concrete mix design. OPC produced by YTL was chosen since Ordinary Portland is certified by MS 522-1: 2007 which used as the binder [8].

River sand that used in this experiment is passing through $4.75 \mathrm{~mm}$ sieve analysis, and the result of the specific gravity of sand is 2.56 was selected as fine aggregate. While for the coarse aggregate was compacted into the granite aggregate that in the range of $9.5 \mathrm{~mm}$ till $37.5 \mathrm{~mm}$. Eggshell was retrieved from Eggtech Manufacturing Sdn Bhd. The eggshells were cleansed with tap water after retrieving from the factory and dried under the sun for 24 hours. Then, the eggshells were ground into powder form which passing through $45 \mu \mathrm{m}$ and used as partial cement replacement at 5\%, $10 \%, 15 \%$ and $20 \%$.

The detail of the mix proportion was tabulated in Table 1. In addition, the detail for each eggshell concrete specimens shown in Table 2.

TABLE I

MiX PROPORTION OF CONCRETE SPECIMENS

\begin{tabular}{|l|c|}
\hline \multicolumn{1}{|c|}{ Materials } & Quantity $\left(\mathbf{k g} / \mathbf{m}^{\mathbf{3}}\right)$ \\
\hline Cement & 400 \\
\hline Coarse aggregate & 1120 \\
\hline River sand & 690 \\
\hline Water-cement ratio & 0.45 \\
\hline
\end{tabular}

TABLE II

DETAIL OF EGGSHELl CONCRETE

\begin{tabular}{|c|c|}
\hline Eggshell powder (\%) & Air dried eggshell \\
\hline 5 & WA 5 \\
\hline 10 & WA 10 \\
\hline 15 & WA15 \\
\hline 20 & WA 20 \\
\hline
\end{tabular}

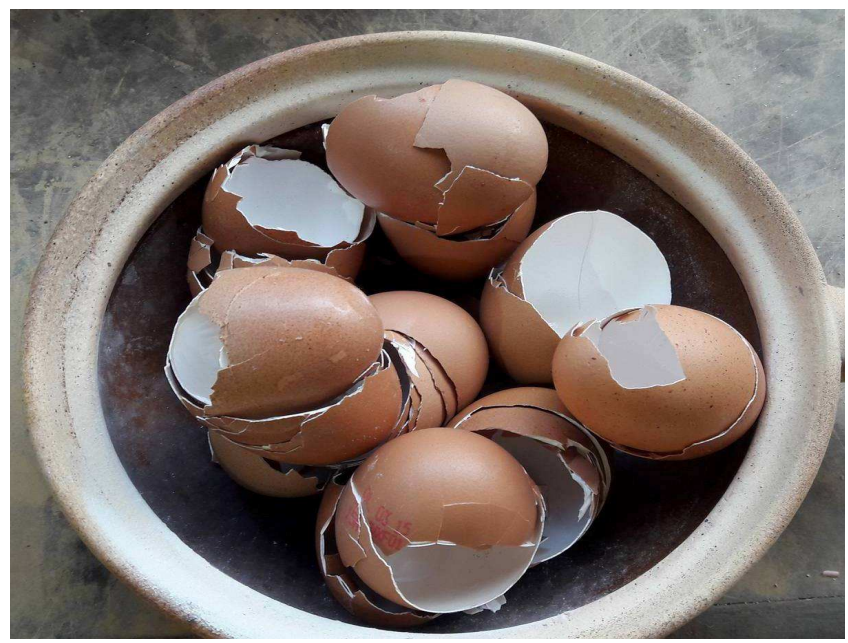

Fig. 1 Raw eggshell before undergo grinding process

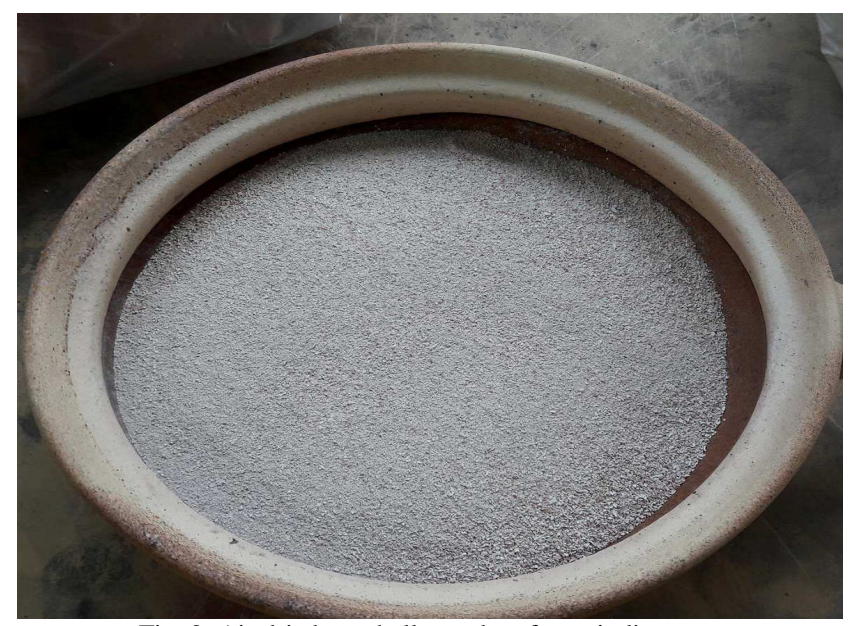

Fig. 2 Air dried eggshell powder after grinding process

\section{B. X-Ray Diffraction Analsysis (XRD)}

$\mathrm{X}$-ray diffraction (XRD) analysis was selected to perform analysis on the eggshell powder samples. The XRD analysis results were reported by using Philips X'Pert Pro Diffraction with $\mathrm{Cu} \mathrm{K} \alpha$ radiation at an operating voltage of $45 \mathrm{kV}$, and a current of $40 \mathrm{~mA}$ and the scanning speed in this experiment was $0.02 \% \mathrm{~min}$. In addition, the measurement of the pattern was performed at the angle of 2 theta/theta that ranges between $3^{\circ}$ and $80^{\circ}$.

Through XRD, it is able to determine the crystalline structure and qualitative composition after the grinding process for the eggshell powders.

\section{Slump Test}

Slump test was performed to determine the workability of the fresh concrete. The slump test procedure complies with BS 1881: Part 102 [9].

\section{Compressive Strength Test}

Concrete cube $100 \mathrm{~mm}$ x $100 \mathrm{~mm}$ x $100 \mathrm{~mm}$ was selected to perform compressive strength analysis by compression machine MATEST with a loading rate of $0.25 \mathrm{~N} / \mathrm{mm} 2 / \mathrm{sec}$ as shown in Fig. 3. All of the concrete cubes samples were undergo curing in a water tank until the testing day of 1,7 , 28, 56 and 90. The compressive strength test procedure complies with BS 1881: Part 116 [10]. 


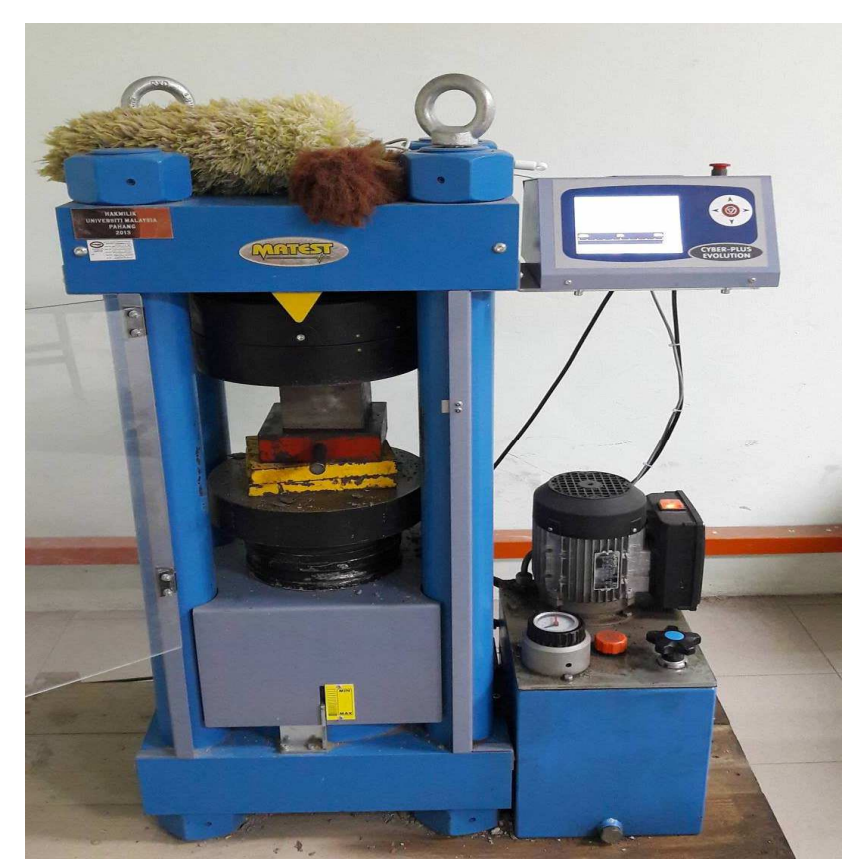

Fig. 3 Compression machine MATEST to perform compressive strength test on concrete cube specimens

\section{E. Flexural Strength Test}

Beam size with $100 \mathrm{~mm}$ x $100 \mathrm{~mm}$ x $500 \mathrm{~mm}$ was selected to perform flexural strength test. The flexural strength analysis was performed by using Universal Testing Machine with a loading rate of $0.03 \mathrm{~N} / \mathrm{mm} 2 / \mathrm{sec}$ as shown in Fig. 4. The flexural strength test procedure complies with BS 1881: Part 118 [11].

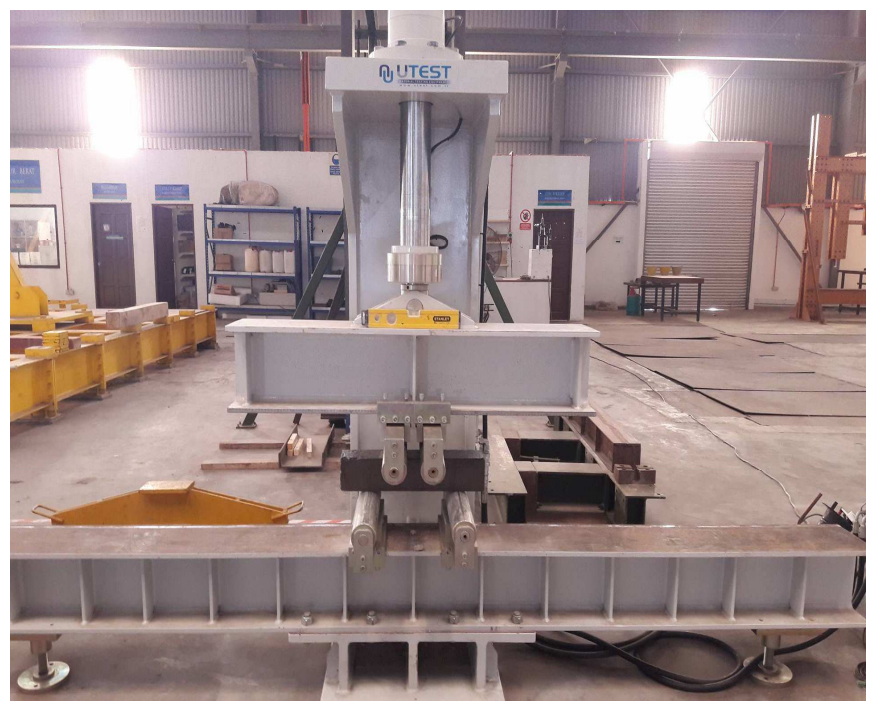

Fig. 4 Universal Testing Machine to perform flexural strength test on concrete beam specimens

\section{F. Water Absorption Test}

Water absorption test was performed to identify the ability of the rate of water absorption of the concrete specimens. The concrete cube size $100 \mathrm{~mm}$ x $100 \mathrm{~mm} \times 100$ $\mathrm{mm}$ was selected to perform water absorption test. The concrete cubes specimens were dried in the oven at $105.5^{\circ} \mathrm{C}$ for 24 hours. The initial weight of the specimens was measured. Then the specimens were submerged in the water, and the surface was wiped dry before the weight of the specimens was taken. The concrete cubes were repeatedly measured at $1,5,10,15,30,60,120,180,1440,2880$ and 4320 minutes. The testing procedure was conducted according to BS 1881: Part 122 [12].

\section{G. Microstructure Characterization}

Scanning electron microscope (SEM) was used to investigate the microstructure of the eggshell concrete samples. The SEM model was Hitachi TM 3030 Plus.

The samples were placed on a small stub by using doublesided tape. Scanning electron microscope is able to provide better resolution of the internal structure of the eggshell concrete.

\section{RESULT AND DISCUSSION}

\section{A. XRD Analysis}

The XRD result patterns of the eggshell powder in the investigation are illustrated in Fig. 5. During the making of the eggshell powder, the most of the eggshell membrane that available in the was removed since it considered as an amorphous group that XRD don is not shown any result of it [13].

Characteristics crystalline of the XRD result peaks showed the majority is calcium carbonate $(\mathrm{CaCO} 3)$, it is in the form of calcite to acts as the main materials for the eggshell powders. Calcite was described to be the most thermodynamically stable under ambient condition [14].

The XRD result, the peaks for the calcite showed at around the $2 \theta$ angles of; $23.64^{\circ}, 29.1^{\circ}, 36.54^{\circ}, 39.5^{\circ}, 44.1^{\circ}$, $47.1^{\circ}, 49.44^{\circ}, 57.2^{\circ}, 62.5^{\circ}, 70.1^{\circ}, 72.24^{\circ}$ and $77.8^{\circ}$ with the highest peak around $29.1^{\circ}$. The concentrations of the calcite peaks were showed with no other form crystalline phase formed as similar as previous investigation [15].

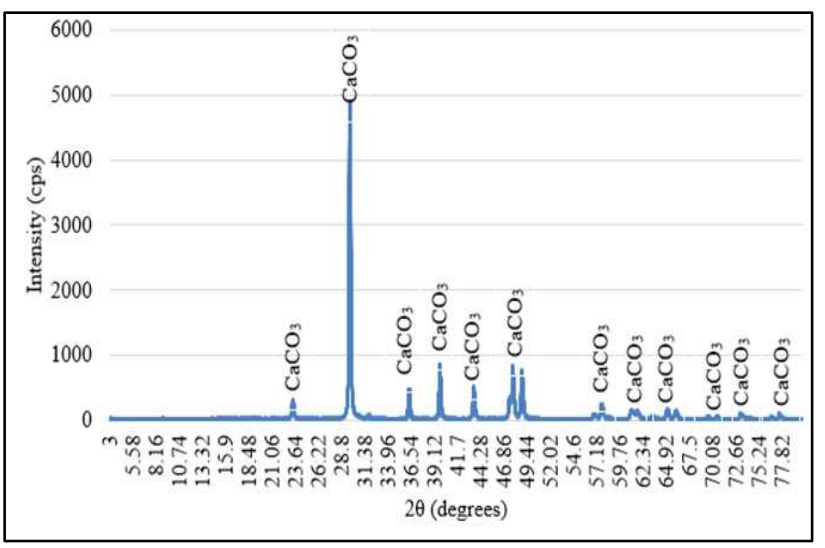

Fig. 5 XRD pattern of eggshell powder

\section{B. Slump Test}

In this research, the slump test was conducted for concrete with a variety of proportion of eggshell powder treated as the partial cement replacement. The result of the slump results was tabulated in Table 3 . The highest slump result of the was WA $20 \%$ of $80 \mathrm{~mm}$ while the lowest slump result was WA $5 \%$ of $63 \mathrm{~mm}$. Fig. 6 indicated that all the slump results were fell under the acceptable range of $75 \pm 25 \mathrm{~mm}$. All the value for the concrete specimens is known as a true slump.

From the slump test result, the addition of the eggshell powder does not affect much on the workability of the fresh concrete. Thus, it able to improve the workability of the 
concrete. Since the workability is an essential criterion in concrete as the workable mix will produce sound concrete, which can be considered as well compacted, transported and placed without any segregation. According to the Table 3, all of the concrete mixes are considered as medium workability and able to produce compact concrete.

TABLE III

SLUMP TEST RESUlt

\begin{tabular}{|c|c|c|}
\hline Sample & Percentage (\%) & Slump $(\mathbf{m m})$ \\
\hline C & 0 & 76 \\
\hline WA 5 & 5 & 63 \\
\hline WA 10 & 10 & 72 \\
\hline WA 15 & 15 & 78 \\
\hline WA 20 & 20 & 80 \\
\hline
\end{tabular}

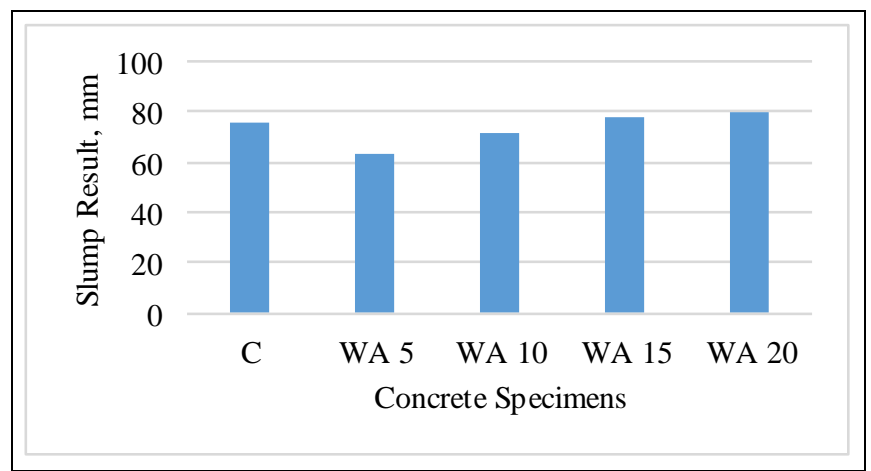

Fig. 6 Slump test with different percentage of cement replacement

\section{Compressive Strength Test}

Compressive strength test is one of the essential parameters of the hardened concrete. In this research, the eggshell concrete was being analysis at the concrete age of 1 , 7, 28, 56 and 90 days. Fig. 9 illustrate the eggshell concrete cube specimens after compressive strength test.

The results of the compressive strength of the concrete cube specimens were illustrated in Fig. 7. It clearly showed that the eggshell concrete had high early strength, most of the compressive strength of the eggshell concrete had achieved more than $25 \mathrm{MPa}$ at the concrete age of one day. While the control specimen with zero percentage of eggshell powder only reached $12 \mathrm{MPa}$ at day 1 . At the age 90 days, WA 15 had the highest compressive strength of $51 \mathrm{MPa}$ while the control specimen only showed $36 \mathrm{MPa}$. Although the compressive strength of the concrete drop when the replacement went up to $20 \%$, The compressive strength is still higher than the control specimen by $11 \%$. From Fig. 8 , the most optimum percentage of using eggshell powder was $15 \%$.

The compressive strength for all the eggshell concrete specimens had higher compressive strength as the enhancement of the internal pore structure and has lesser porosity. This is because there is the high degree of hydration process during the curing environment which allows less moisture faded to the atmosphere. Loss of the moisture of the concrete during the early days of the concrete age may interrupt the hydration process, and it may cause severe consequence to the concrete microstructure [16].

As eggshell concrete provides extra calcium hydroxide to the concrete, which is responsible for the compressive strength development. Thus, with the proper curing eggshell concrete achieved higher and better compressive strength than normal control specimens. One of the reason is the undisturbed hydration process may generate a larger amount of the calcium-silicate-hydrate gel (C-S-H) which act as an essential part of improving the engineering performance of concrete through densification of the concrete internal structure.

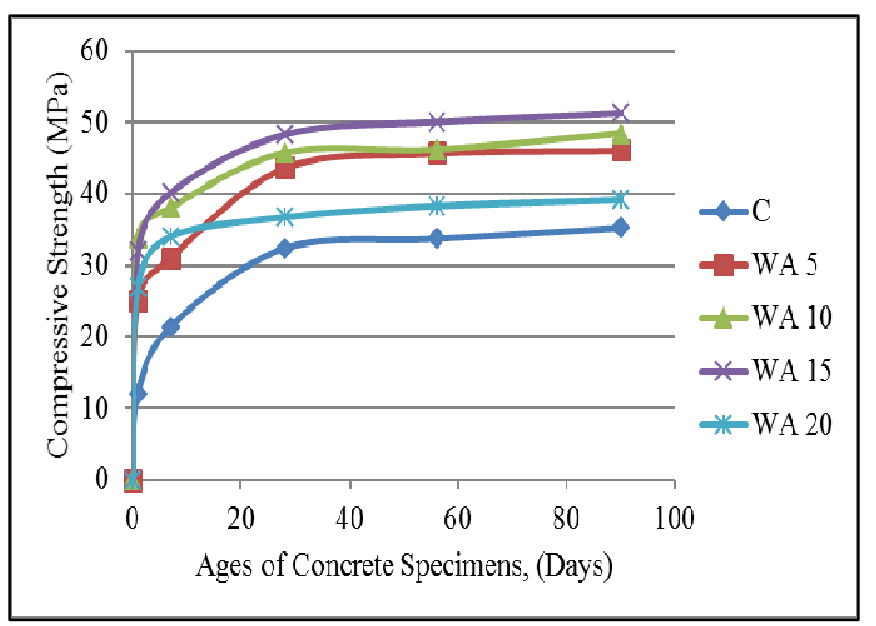

Fig. 7 Compressive strength of concrete specimens

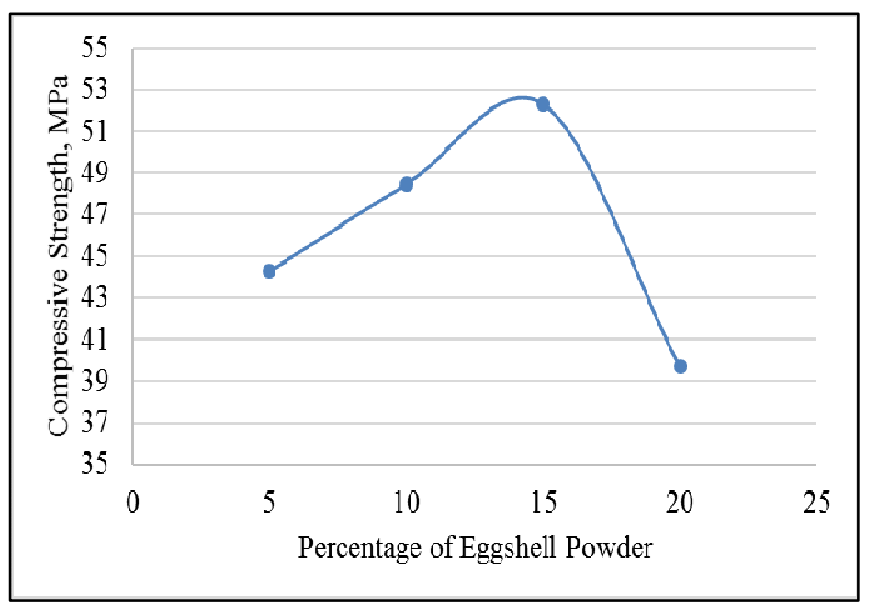

Fig. 8 The effect of eggshell to compressive strength

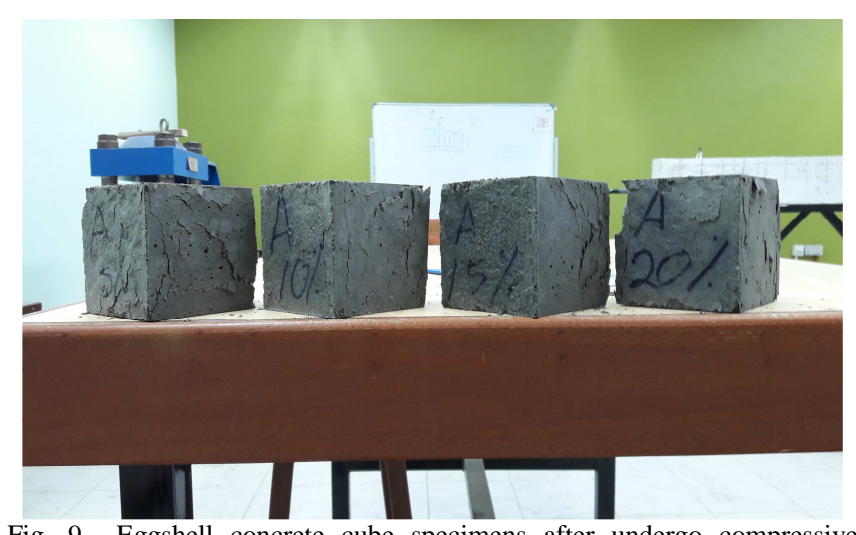

Fig. 9 Eggshell concrete cube specimens after undergo compressive strength test 


\section{Flexure Strength Test}

The flexural strength test was conducted at the concrete age of 1, 7, 28, 56 and 90 days. Fig. 12 shows the pattern of the eggshell concrete beam specimens after undergo flexural strength test.

Fig. 10 illustrated the flexural strength of the concrete specimens with varying percentage of eggshell powders in the investigation. The highest flexural strength of the eggshell concrete was $10.2 \mathrm{MPa}$ with $15 \%$ of eggshell powder replacement. The result showed that $15 \%$ of partial cement replacement able to increase the flexural strength up to $45 \%$ compared to normal control specimens. From Fig. 10, is observed that the flexural strength increases up to $45 \%$ with eggshell replacement up to that after using eggshell powder as a cement replacement, it can greatly improve the flexural strength of the concrete up to $45 \%$. The result was confirmed by Sivakumar [17]. From Fig. 11, it showed that the flexural strength of the concrete tend to drop when the cement replacement was up to $20 \%$. This is the same trend that illustrated in the compressive strength result in Fig. 8.

Realizing that calcium hydrate product is known as the essential element in hydration process in order to strengthen the strength of the concrete since the concrete beams are all subjected to the full water curing and exhibit continuous strength development throughout the curing age as shown in Fig. 9. Eggshell provide extra calcium hydroxide in the presence of the continuous of moisture leading to the formation of secondary calcium-silicate-hydrate gel [18]. The incidence of the hydration process of the eggshell concrete had increased the quantity of the calcium hydrate products. Furthermore, the fineness of the eggshell powder also acts as a good filler by filling in the internal voids of the concrete and lead to the structure more packed and improve the strength development.

Looking at the effect of the full water curing, it is evident that the strength development of the eggshell concrete. a continuous supply of moisture allows the undisturbed hydration process as well as pozzolanic reaction to take place thus generating a larger amount of calcium-silicatehydrate gel filling in the concrete pores. This helps the water cured eggshell concrete possess denser internal structure and thus exhibit higher strength.

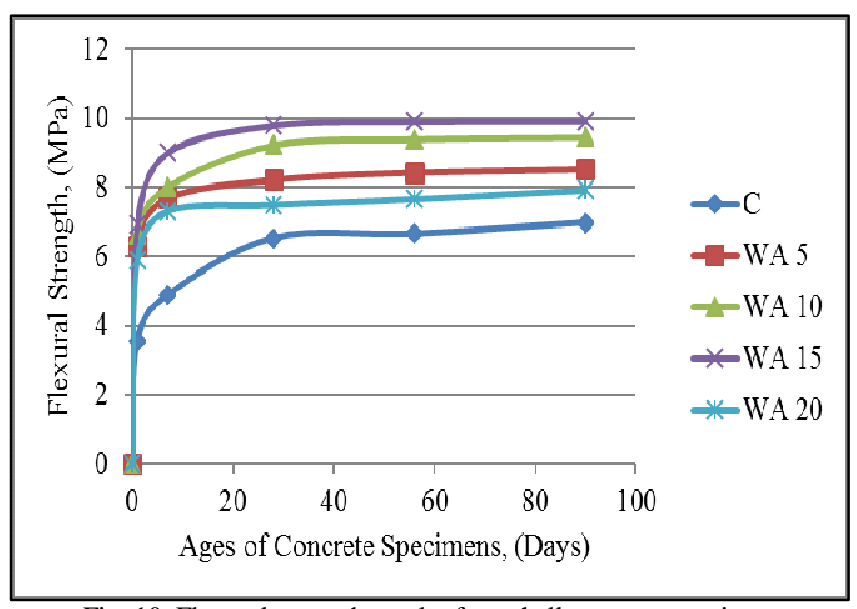

Fig. 10 Flexural strength result of eggshell concrete specimens

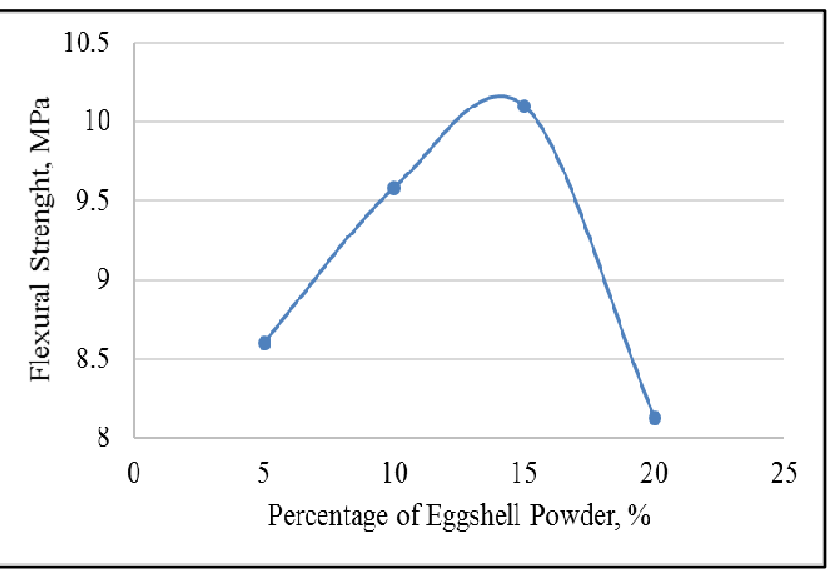

Fig. 11 The effect of eggshell powder to flexural strength

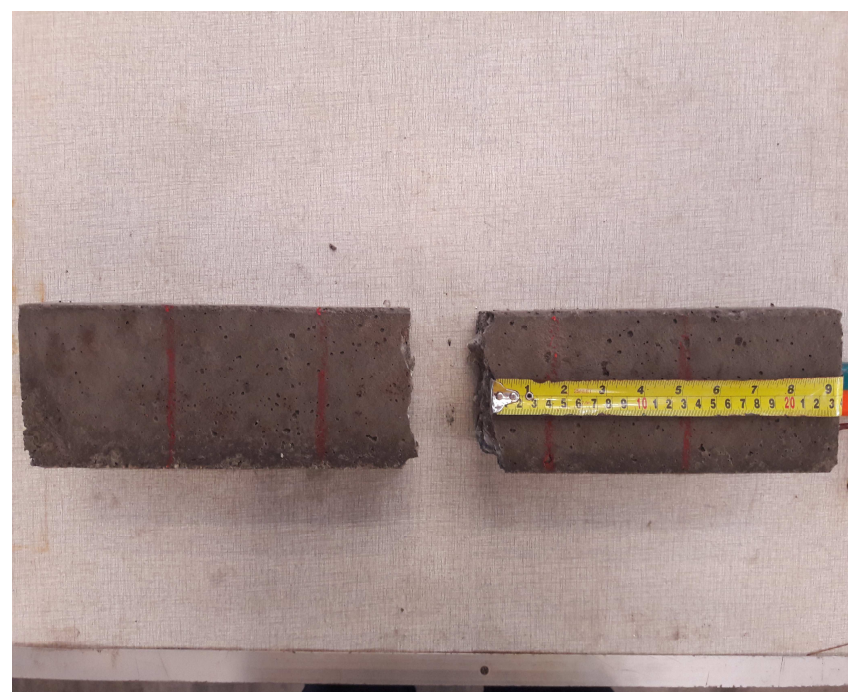

Fig. 12 Eggshell concrete beam specimens after undergo flexural strength test

\section{E. Water Absorption Test}

Water absorption was carried out to identify the ability of the rate of water absorption of the concrete specimens. This test was conducted on 28 days. Fig. 13 illustrated the rate of water absorption of the concrete specimens. It reveals that the rate of water absorption of eggshell concrete specimens was greatly reduced after replacing by eggshell powder from $5 \%$ to $20 \%$. Fig. 14 provide the initial rate of water absorption of eggshell powder. It found out that WA 5 had the highest initial rate of water absorption than other eggshell concrete specimens. As the amount of the eggshell is lower than others, Doh et al. [3] found out that eggshell powder may be a good filler to concrete. As a result, in this investigation eggshell powder provide a more secondary calcium-silicate-hydrate gel which may fill up the internal voids of the concrete. Thus eggshell concrete had a lower rate of water absorption [19].

During the water curing process of the eggshell concrete had provided sufficient moisture that allows the hydration process to be more complete. Thus, the amount of the calcium-silicate-hydrate gel is higher than the normal control concrete specimens. As the voids of the eggshell concrete in the internal structure is lesser, water absorption for eggshell concrete has a lower rate. The unreacted eggshell powder will act as filler and fill up the existing voids [3]. Since the compressive strength for the WO $20 \%$ is lower than WO 5\%, 
as there is a limited amount of silicon dioxide that available to react with calcium hydroxide to produce a secondary C-S$\mathrm{H}$ gel. As a result, the unreacted eggshell powder treated as filler in the concrete. Thus, the rate of water absorption for WO $20 \%$ is lower than WO $5 \%$.

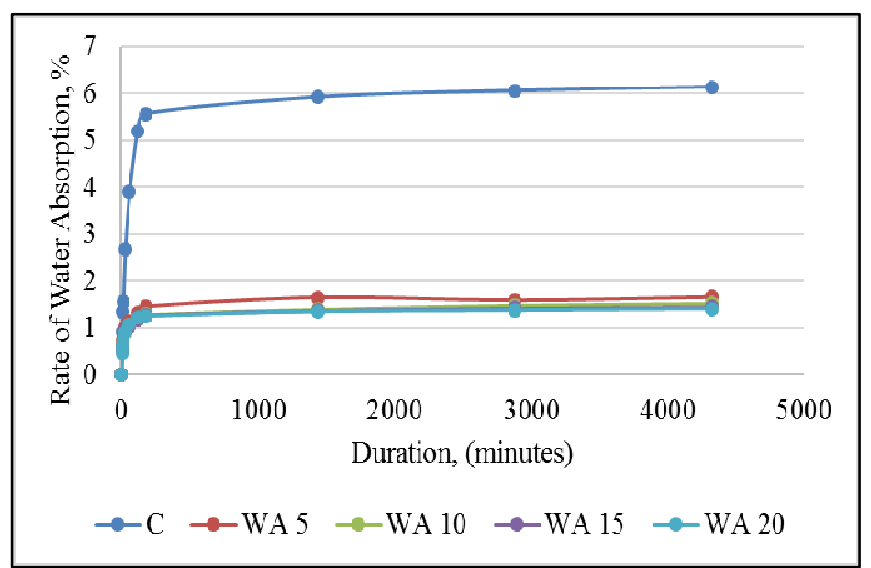

Fig. 13 The rate of water absorption of concrete specimens

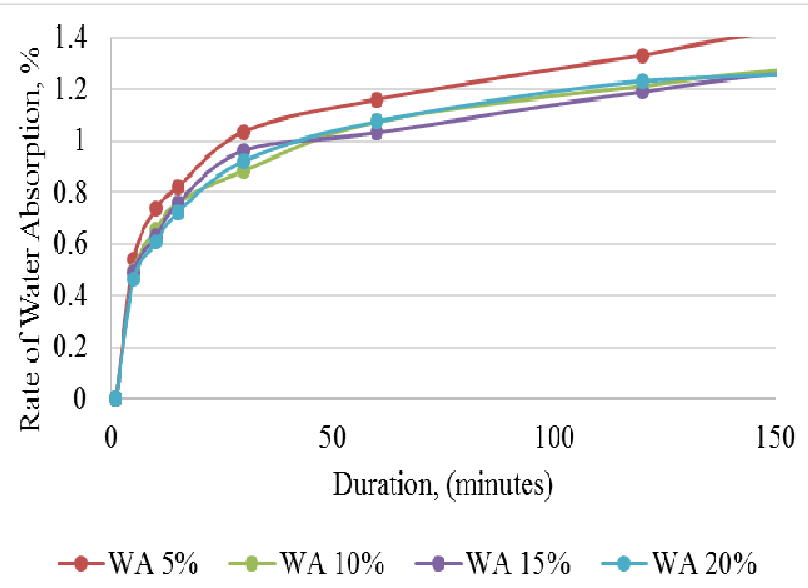

Fig. 14 The rate of water absorption at initial time

\section{F. Scanning Electron Microscope}

Scanning electron microscope was conducted to provide a better resolution of the eggshell concrete specimens. Fig. 15 illustrated the better resolution of the eggshell concrete. It was obvious that the voids had been significantly decreasing in the eggshell in Fig. 16. This is the reason, the rate of water absorption for eggshell concrete is lower than since there are fewer voids to allow the water to flow in. As the water absorption rate of the control specimens is higher as it has a large number of voids that available in the concrete. It can clearly see in Fig. 13 the voids of the normal control specimens can be easily observed.

By adding the eggshell powder to the concrete had provided additional of calcium oxide which is an important component in producing secondary calcium-silicate-hydrate gel [17]. Thus, eggshell can be used as partial cement replacement without affecting the water absorption rate. The increment of the voids in the internal structure of the concrete specimen may reduce the strength of it. As the eggshell concrete had a better strength development compared to the control specimens as illustrated in Fig. 7 and 10 . As a result, the eggshell powder may to reduce the number of the voids in the internal structure of the concrete and enhance the internal structure of the concrete as well as improve the compressive strength.

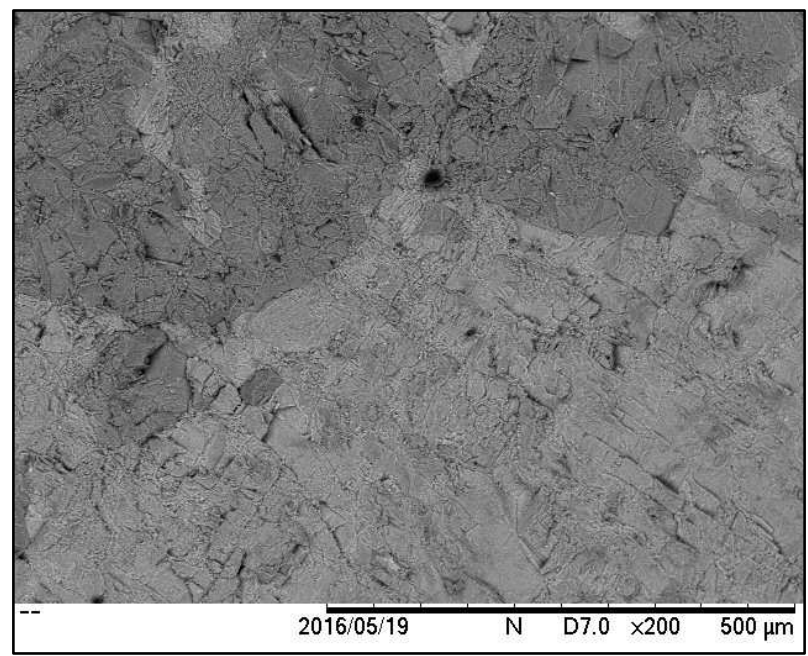

Fig. 15 SEM result of WA 15

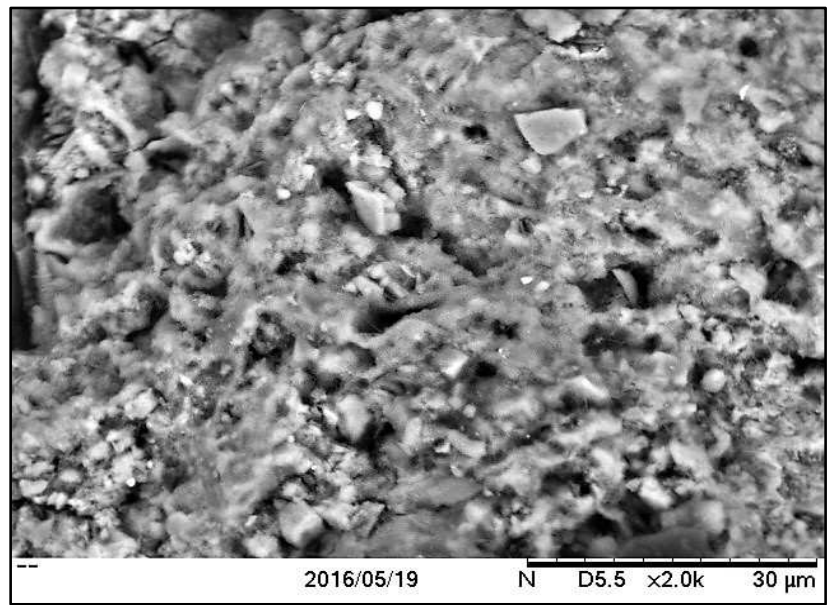

Fig. 16 SEM result of control specimen without eggshell powder

\section{CONCLUSION}

From the investigation, the following conclusion can be obtained. The partial cement replacement with eggshell powder has improved the compressive strength of the concrete. $15 \%$ is the most optimum percentage in order to improve the compressive strength up to $51 \mathrm{MPa}$ at the concrete age of 90 days.

The partial cement replacement with eggshell powder has improved the flexural strength of the concrete. The highest flexural strength of the eggshell concrete was 10.2 MPa. The involvement of the eggshell powder had greatly improved the flexural strength up to $45 \%$.

The rate of water absorption was significantly reduced when replaced with eggshell powder. Since eggshell powder is able to greatly fill up the internal voids by providing secondary calcium-silicate-hydrate gel with extra calcium that available in the eggshell. 


\section{ACKNOWLEDGMENT}

The authors would like to thanks the Eggtech Manufacturing Sdn Bhd for donations of the eggshells.

\section{REFERENCES}

[1] F. Raupiy, A. Saggaff. C.S. Tan, Y.L. Lee, and M.M. Tahir, "Splitting tensile strength of lightweight foamed concrete with polypropylene fiber," International Journal on Advanced Science Engineering Information Technology, vol. 7, no. 2, pp.424-430, 2011.

[2] P.K. Acharya, and S.K. Patro, "Acid resistance, sulphate resistance and strength properties of concrete containing ferrochrome ash (FA) and lime," Construction and Building Materials, vol. 120, pp. 241250, 2016.

[3] M. Dhanalakshimi, N.J. Sowmya, and A. Chandrashekar, "A comparative study on eggshell concrete with partial cement replacement of cement by fly ash," International Journal of Engineering Research and Technology, vol. 4, no. 5, pp. 1532-1538, 2015.

[4] S.I. Doh, S.C. Chin, and A. Suil, "Eggshell powder: potential filler in concrete," $8^{\text {th }}$ MUCET, 2014.

[5] Shah,C.J., Pathak, V.B. and Shah, R.A. "A study of future trend for sustainable development by incorporation of supplementary cementitious material's," IJIES, vol. 1, no. 11, pp. 19-26, 2013.

[6] F.V. Riza, I.A. Rahman, and A.M.A Zaidi, "Possibility of lime as a stabilizer in compressed earth brick (CEB)," Proceeding of the International Conference of Advanced Science, Engineering and Information Technology, 14-15 January 2011.

[7] J.R. Roberts, "Factors affecting egg internal quality and egg shell quality in laying hens," Journal of Poultry Science, vol. 41, no. 3, pp. 161-177, 2004.

[8] BS EN 196-1:2000. "Cement," Composition, specifications and conformity criteria for common cements, 2000.
[9] British Standard Institutions. "Method for determination of slump,' London BS 1881: Part 102, 1983.

[10] British Standard Institution. "Method for determination of compressive strength of concrete cube," London BS 1881: Part 116 , 1983.

[11] British Standard Institution. "Method for determination of flexural strength," London BS 1881: Part 118, 1983.

[12] British Standard Institution. "Method for determination of water absorption," London BS 1881: Part 122.

[13] P. Pliya, and D. Cree, "Limestone derived eggshell powder as replacement in Portland cement mortar," Construction and Building Materials, vol. 95, pp. 1-9, 2015.

[14] L.N. Schultz, K.N. Andeson, D. Dably, D.V. Muter, H. Okhrimenko, and Fordsmand. "High surface area calcite," Journal Crystal Growth, vol. 371, pp. 34-38, 2013

[15] P. Intharapat, A. Kongnoo, and K. Kateungngan, "The potential of chicken eggshell waste as a bio filler epoxide natural rubber (ENR) composites and its properties," Journal Polymer Environment, vol. 21 , no. 1 , pp. 245-258, 2013

[16] W.K. Norul, and M. Khairunisa, "Effect of curing regime on compressive strength of concrete containing Malaysian laterite aggregate," Advanced Materials Research, vol. 626, pp. 839-843, 2013.

[17] M. Sivakumar, and N. Mahendran, "Strength and permeability properties of concrete using fly ash, rice hush ash and eggshell powder," Journal of Theoretical and Applied Information Technology, vol. 66, no. 2, pp. 489-499, 2014.

[18] M.Y. Fadzil, M. Khairunisa, and W.H. Mohd, "Effect of curing regime on compressive strength of aerated concrete containing palm oil fuel ash as partial cement replacement," Concrete Research Letters, vol. 6, no. 2, pp. 54-59, 2015.

[19] U.N. Okonkwo, I.C. Odiong, and E.E. Akpabio, "The effects of eggshell ash on strength properties of cement-stabilized lateritic," International Journal of Sustainable Construction Engineering and Technology, vol. 3, no. 1, pp. 18-25, 2012. 